J. clin. Path., 1975, 28, 274-278

\title{
Reevaluation of bacteriocinogeny in Neisseria gonorrhoeae
}

\author{
JOAN SKERMAN KNAPP, STANLEY FALKOW, AND KING K. HOLMES
}

From the Departments of Medicine and Microbiology, University of Washington School of Medicine, and the US Public Health Service Hospital, Seattle, Washington

SYNOPSIS Bacteriocin typing has been described previously and proposed for typing gonococci. A survey has been made of 150 strains of $N$. gonorrhoeae from various places to determine the feasibility of a gonocin typing system. All strains were found to produce an inhibitory substance which inhibited all strains of gonococci tested, one strain of Neisseria flavescens, two strains of Neisseria meningitidis, as well as the producing strain itself. The inhibitory activity was enhanced by supplementary glucose, reduced by supplementary serum, and unaffected by the addition of HEPES buffer, by the temperature of incubation, or by the exposure of potential producer strains to sublethal concentrations of mitomycin $\mathbf{C}$. This nonspecific inhibitory activity differed from that of a putative bacteriocin produced by a strain of $N$. meningitidis, in that the latter inhibited most other meningococci but not the producer strain itself. Bacteriocinogeny has not yet been convincingly demonstrated in $N$. gonorrhoeae, and gonocin typing has not yet been shown to be feasible. Production of the nonspecific inhibitor may have obscured past attempts to demonstrate type-specific gonococcal bacteriocin.

Bacteriocins are a unique class of antibiotics which differ from other antibiotics in that bacteriocins elaborated by one species are usually active only against a proportion of strains of the same or closely related species (Hamon and Peron, 1960; Reeves, 1965). This limited spectrum is particularly characteristic of bacteriocins of Gram-negative bacteria. With few possible exceptions (Goodwin, Levin, and Doggett, 1972), bacteriocins are not active against the bacterial strains which elaborate them.

Bacteriocin typing systems have been used widely in epidemiological studies of many bacterial species. Bacteriocinogeny was first described in N. meningitidis in 1966 (Kingsbury, 1966), and variation in susceptibility to meningococcal bacteriocins has been used as a tool to identify virulent strains of $N$. meningitidis (Counts, Seeley, and Beaty, 1971). Flynn and McEnteggart (1971) detected bacteriocin-like activity in $75 \%$ of gonococci examined and found 13

\footnotetext{
${ }^{1}$ This research was supported by contract no. HSM 21-73-535 with the Center for Disease Control, Health Services and Mental Health Administration, Department of Health, Education, and Welfare, and by Federal Health Programs Service Project SEA (Y)-73-6-72.

'Reprint requests to: Dr Holmes, US Public Health Service Hospital, 1131 Fourteenth Avenue South Seattle, Washington 98114

Received for publication 27 November 1974.
}

patterns of inhibition of six indicator strains. They suggested that these patterns were sufficiently distinctive to permit a typing system, based upon bacteriocin production, to be applied in epidemiological studies of gonococcal infections. This report describes a search for gonocin production, and the detection of a nonspecific inhibitor produced by $N$. gonorrhoeae.

\section{Materials and Methods}

SELECTION OF ISOLATES TESTED

Strains of $N$. gonorrhoeae tested for bacteriocin production included 88 fresh isolates recovered from patients in Seattle (two had gonococcal arthritis and one had salpingitis), four isolates from the Philippines, 17 provided by Dr James Plorde from Ethiopia, 19 provided by Dr James Gale from Taiwan, 21 provided by Dr Alice Reyn from Denmark, and one previously reported to produce bacteriocin (gonocin) and provided by Drs W. D. Lawton and H. A. Gaafar (Lawton and Gaafar, 1973). These isolates were tested in groups of 19 together with a strain of $N$. meningitidis serogroup $\mathrm{B}$, strain 51 , which produces a highly active inhibitor of meningococci and gonococci, and was provided by Dr Harry Beaty for use as a control in each experiment. Each set of strains was tested for production of bacterio- 
cin-like activity against every other strain in that set, as well as against a group of five indicator strains which had previously been found by Flynn and McEnteggart to be susceptible to gonocin and were kindly provided by Dr Flynn. Other Neisseria species tested as indicators for susceptibility to gonocin were provided by Dr B Wesley Catlin.

\section{METHOD OF TESTING FOR BACTERIOCIN}

PRODUCTION

Each isolate was grown on chocolate blood agar or on Difco GC base medium containing $1 \%$ defined supplement (GCBDS; White and Kellogg, 1965) at $35^{\circ} \mathrm{C}$ in air plus $5 \% \mathrm{CO}_{2}$. All strains werc maintained at $-70^{\circ} \mathrm{C}$ in a $50: 50$ solution of gamma globulin-free horse serum (BBL) and tryptic soy broth (Difco).

Preliminary tests for gonocin were made on GCBDS medium and on chocolate blood agar, using the method of Flynn and McEnteggart, 1971) and employing the five indicator strains provided by these authors. As described by Flynn and McEnteggart, inhibitory activity on chocolate blood agar was weaker and less consistent than on the GCBDS medium, and the use of chocolate blood agar was discontinued. Inhibitory activity on GCBDS medium was rarely observed after 24 hours' incubation, was only sometimes observed after 48 hours' incubation, and the results for the same strains tested under the same conditions were not always reproducible. On occasion, however, complete removal of the growth from the agar surface after 48 hours was difficult, and it was discovered that all indicator strains were consistently inhibited around any remnants of growth, with an inhibition zone of 1 to $3 \mathrm{~mm}$ width. Remnants of growth of any given strain also gave a similar zone of inhibition even when that same strain was employed as an indicator. Subsequently, therefore, tests for inhibitory activity of $N$. gonorrhoeae strains were made after 24-hr and 48-hr incubation periods, both when growth was and was not removed before inoculation with the indicator strain.

All tests were made on GCBDS medium dispensed in $50-\mathrm{ml}$ volumes in $150-\mathrm{mm}$ petri plates. Inocula were prepared from overnight growth on solid medium, which was suspended in Difco nutrient broth to an optical density of 0.2 at $540 \mathrm{~nm}$ in a Bausch and Lomb spectronic 20 colorimeter. A Steers replicator was employed to inoculate 0.0025 $\mathrm{ml}$ of each culture suspension containing approximately $1 \times 10^{8}$ colony-forming units per ml onto four sets of identical plates which were incubated for 24 or 48 hours at $35^{\circ} \mathrm{C}$ in air plus $5 \% \mathrm{CO}_{2}$.

All growth was removed from the agar surface with a glass slide, followed by a cotton swab from two sets of plates at 24 and 48 hours, respectively. The plates were then exposed to chloroform vapour for $15 \mathrm{~min}$, followed by exposure to air for 30 minutes. The remaining two sets of plates were similarly exposed to chloroform at 24 and 48 hours without removal of the growth.

Indicator strains were prepared in the same manner as the initial inocula, but were adjusted to an optical density of $0 \cdot 1$ at $540 \mathrm{~nm}$. After exposure to chloroform and air the plates were flooded with $5.0 \mathrm{ml}$ of the indicator suspension, and the excess was decanted before incubation at $35^{\circ} \mathrm{C}$ in air plus $5 \%$ $\mathrm{CO}_{2}$. Plates were examined at 24 hours for inhibition of the indicator strains.

EFFECT OF GLUCOSE, SERUM, HEPES BUFFER, AND TEMPERATURE OF INCUBATION ON

INHIBITORY ACTIVITY

In separate experiments, the effect of glucose, serum, and Hepes buffer on inhibitory activity, observed on GCBDS medium, was evaluated by the omission of supplementary glucose from the GCBDS medium; by the addition of $10 \%$ horse serum (BBL) heated at $56^{\circ} \mathrm{C}$ for $30 \mathrm{~min}$; and by the addition to GCBDS medium of Hepes buffer to a final concentration of $0.03 \mathrm{M}$, followed by adjustment of the $\mathrm{pH}$ to $7 \cdot 4$. Observations were made after 24 and 48 hours without removal of the basal growth, as described above. The effect of temperature of incubation was also determined by comparing the level of activity obtained incubating both the inhibitory and indicator strains on GCBDS medium at $28^{\circ} \mathrm{C}$ with that obtained by incubating at $35^{\circ} \mathrm{C}$.

\section{DIFFUSIBILITY OF INHIBITOR}

Because preliminary experiments showed that inhibitory activity was variably removed with removal of surface growth of the producing strain of $N$. gonorrhoeae the above method was modified by an additional step to determine whether the inhibitory activity was cell-associated or diffusible. Following exposure to chloroform of strains being tested for bacteriocinogeny, a $50 \%$ dilution of GCBDS medium was cooled to $50^{\circ} \mathrm{C}$, then overlaid to a thickness of approximately $1 \mathrm{~mm}$ over the producer colonies. When the overlay had hardened, the plates were then flooded with $5.0 \mathrm{ml}$ of the indicator strain suspension, as described above.

TREATMENT WITH MITOMYCIN C The minimal inhibitory concentrations (MICs) of mitomycin $\mathrm{C}$ were determined for eight strains of $N$. gonorrhoeae. Colonies of $N$. gonorrhoeae scraped from the surface of GCBDS medium after 24 hours' incubation were suspended in nutrient broth to an optical density of 0.15 at $540 \mathrm{~nm}$, and then applied 
with a Steers replicator to GCBDS medium containing serial dilutions of mitomycin C. The MIC was defined as the concentration which completely inhibited growth after incubation for 24 hours at $35^{\circ} \mathrm{C}$ in air plus $\mathrm{CO}_{2}$, and ranged from 0.04 to $0.1 \mu \mathrm{g}$ per $\mathrm{ml}$ for the strains examined. Colonies which grew on $0.02 \mu \mathrm{g}$ mitomycin $\mathrm{C}$ per $\mathrm{ml}$ were tested for bacteriocin production, as described above. In addition, these eight strains were tested for bacteriocin production directly on GCBDS medium containing $0.02 \mu \mathrm{g}$ mitomycin $\mathrm{C}$ per $\mathrm{ml}$.

\section{ULTRA VIOLET IRRADIATION}

Strains of Neisseria gonorrhoeae were suspended in buffered salt solution (Clowes and Hayes, 1968) to an optical density of 0.15 at $540 \mathrm{~nm}$. Seven millilitre aliquots of each strain were placed in a $90 \mathrm{~mm}$ diameter petri plate and were exposed to uv irradiation at $1200 \mathrm{ergs}$ per $\mathrm{cm}^{2}$ per second. A survival curve was constructed for each of the strains and the doses required to give a $10 \%$ survival rate were calculated for each strain. Seven millilitre aliquots of each strain were then exposed to these latter doses and then promptly used to inoculate GCBDS medium and tested for bacteriocin production, as described above.

\section{Results}

One hundred and fifty strains of $N$. gonorrhoeae were tested for their ability to produce a bacteriocin. The results are summarized in table $I$. When growth was removed from the agar surface, antigonococcal activity was shown by six (4.0\%) of 150 strains after 24 hours, and by $33(22.0 \%)$ of 150 strains after 48 hours' incubation. Inhibition zones were small, being limited to the area immediately above where the basal strain had grown and no strain produced inhibition of all indicator strains. By contrast, when the growth was not removed from the agar, antigonococcal activity against all indicators was shown by $147 / 150$ strains after 24 hours and by $150 / 150$ strains after 48 hours. When growth was not removed at 48 hours, every strain produced an inhibitor active against itself. The inhibition zones

\begin{tabular}{|c|c|c|c|c|}
\hline & \multicolumn{2}{|c|}{ Growth Removed } & \multicolumn{2}{|c|}{ Growth Not Removed } \\
\hline & $24 \mathrm{Hr}$ & $48 \mathrm{Hr}$ & $24 \mathrm{Hr}$ & $48 \mathrm{Hr}$ \\
\hline $\begin{array}{l}\text { Inhibition of } \\
\text { any indicator } \\
\text { Inhibltion of } \\
\text { all indicators }\end{array}$ & 6 & 33 & 148 & 150 \\
\hline
\end{tabular}

Table I Inhibition of indicators by 150 strains of $\mathbf{N}$. gonorrhoeae in relation to duration of incubation and removal of growth of the inhibiting strains ranged from 1 to $3 \mathrm{~mm}$, and were often irregular in outline. The size of the inhibitory zones was observed to be correlated with the amount of growth. No colonies resistant to the inhibitory substance were ever observed within the zones of growth inhibition.

The effect of the deletion of glucose, the addition of horse serum, or ithe addition of Hepes buffer was evaluated for 10 producer strains tested against nine indicator strains. All strains tested inhibited every indicator strain after 24 hours' and 48 hours' incubation on complete GCBDS medium. Growth of $N$. gonorrhoeae on GCBDS medium was moderately reduced when glucose was omitted and was slightly enhanced by the addition of horse serum. The inhibitory activity of the 10 producer strains against all nine indicator strains was markedly decreased on GCBDS medium without added glucose, and on GCBDS medium plus $10 \%$ inactivated horse serum. The addition of Hepes buffer to the GCBDS medium had no effect on the inhibitory activity observed in this experiment.

In contrast, as shown in the figure, $N$. meningitidis strain 51 produced a wide symmetrical zone of inhibition against all strains of gonococci employed as indicators. The inhibitory zone was always present after 24 hours' incubation and was not affected by the removal of the surface growth before inoculation with the indicator strains. While $N$. meningitidis strain 51 was itself resistant to this

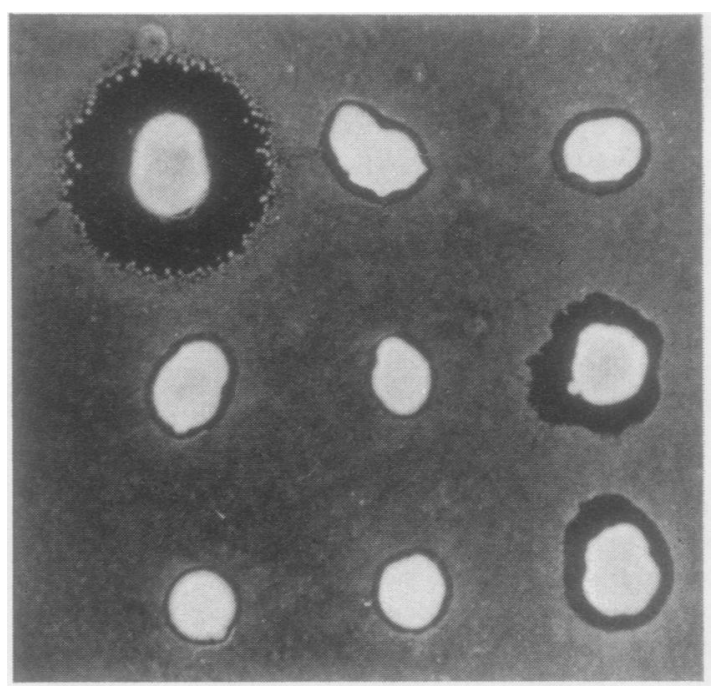

Fig Inhibition of a lawn of a gonococcal indicator strain produced by $\mathbf{N}$. meningitidis strain 51 (upper left corner) and by eight strains of $\mathbf{N}$. gonorrhoeae The indicator strain employed in the lawn is also included as one of the eight producer strains (lower right corner). 
widely diffusible inhibitor, it did exhibit a small irregular zone of inhibition when employed as an indicator inoculated on 48 colonies of the homologous strain 51 . This self-inhibition resembled the nonspecific zones of inhibition produced by all gonococci against all gonococci.

Ten strains of gonococci were tested for inhibition of 10 indicator strains inoculated on the surface of a $1 \mathrm{~mm}$ thick layer of GCBDS agar covering 48-hour-old producer colonies. All 10 strains produced an even circular zone of complete inhibition of all indicators in the area immediately above each producer colony, indicating diffusibility of the inhibitor. All 10 strains exhibited self-inhibition by this method.

Tests for bacteriocin production were made using the same methods but incubating the plates at $28^{\circ} \mathrm{C}$ during growth of both the producer and indicator strains. For those strains which grew at this temperature (nine of 10 tested), the inhibitory effect was the same as that observed at $35^{\circ} \mathrm{C}$.

The activity of 10 strains of $N$. gonorrhoeae was tested against two strains of $N$. meningitidis and six nonpathogenic species of Neisseria. As shown in table II, both strains of $N$. meningitidis were inhibited by all 10 gonococci, and $N$. flavescens ATCC 13120 was inhibited by nine of 10 strains, when the growth of gonococci was not removed from the agar surface. All zones of inhibition were small and irregular. None of the remaining nonpathogenic strains were inhibited by $N$. gonorrhoeae.

\begin{tabular}{|c|c|c|c|c|}
\hline & \multicolumn{2}{|c|}{ Growth Removed } & \multicolumn{2}{|c|}{ Growth Not Removed } \\
\hline & $24 \mathrm{Hr}$ & $48 \mathrm{Hr}$ & $24 \mathrm{Hr}$ & $48 \mathrm{Hr}$ \\
\hline $\begin{array}{l}N . \text { meningitidis } \\
51 \text { (group B) }\end{array}$ & $0 / 10$ & $0 / 10$ & $10 / 10$ & $10 / 10$ \\
\hline $\begin{array}{l}\text { N. meningitidis } \\
\text { HCS4 (group B) }\end{array}$ & $0 / 10$ & $0 / 10$ & $10 / 10$ & $10 / 10$ \\
\hline $\begin{array}{l}\text { N. catarrhalis } \\
\text { Ne } 11 \\
N \text {. flava }\end{array}$ & $0 / 10$ & $0 / 10$ & $0 / 10$ & $0 / 10$ \\
\hline $\begin{array}{l}\text { WRI } 2105 \\
N . \text { flavescens }\end{array}$ & $0 / 10$ & $0 / 10$ & $0 / 10$ & $0 / 10$ \\
\hline $\begin{array}{l}\text { ATCC } 13120 \\
N . \text { perflava }\end{array}$ & $0 / 10$ & $0 / 10$ & $0 / 10$ & $9 / 10$ \\
\hline $\begin{array}{c}\text { Ne } 16 \\
N . \text { mucosa }\end{array}$ & $0 / 10$ & $0 / 10$ & $0 / 10$ & $0 / 10$ \\
\hline CIP 5951 & $0 / 10$ & $0 / 10$ & $0 / 10$ & $0 / 10$ \\
\hline $\begin{array}{r}N . \text { sicca } \\
\mathrm{Ne} 12\end{array}$ & $0 / 10$ & $0 / 10$ & $0 / 10$ & $0 / 10$ \\
\hline
\end{tabular}

Table II Inhibition of two strains of N. meningitidis and six non-pathogenic Neisseria species by 10 strains of $\mathbf{N}$. gonorrhoeae

EFFECT OF MITOMYCIN C AND ULTRAVIOLET IRRADIATION ON PRODUCTION OF INHIBITION

Exposure of eight strains of $N$. gonorrhoeae to mitomycin $\mathrm{C}$ and uv irradiation did not increase the size of the zones of nonspecific inhibition produced by these strains against all other gonococci tested as indicators, or affect production of a qualitatively different inhibitor resembling the putative bacteriocin of $N$. meningitidis.

\section{Discussion}

The inhibitory substance produced by all strains of $N$. gonorrhoeae tested in this study differed from most previously described bacteriocins, and from the bacteriocin-like inhibitor produced by $N$. meningitidis strain 51, in that the former was active against all other strains of gonococci tested and inhibited the strains which produced it. Treatment with mitomycin $\mathrm{C}$ and uv irradiation under conditions employed in this study failed to induce diffusible bacteriocins with type specificity. Although shown to be diffusible, the inhibitor produced by $N$. gonorrhoeae was largely restricted to the surface of the GCBDS medium. The production or expression of this inhibitory substance was independent of incubation temperature, was reduced by the omission of supplementary glucose from the growth medium, and was inhibited by serum. The nature of the inhibiting substance has not been defined. It seems likely that the variable removal of this inhibitor during removal of surface growth previously hindered the detection of production of the inhibitor by all gonococci (Flynn and McEnteggart, 1971).

There may be quantitative differences in production of this nonspecific inhibitor among various strains of $N$. gonorrhoeae. However, under the conditions employed in this study, it is unlikely that such differences will provide the basis for a useful means of differentiating strains of gonoccoci, since no qualitative difference in production of, or susceptibility to, the inhibitor has been observed among gonococci. It seems likely that this inhibitory substance is not a bacteriocin, but that it is a metabolite produced by all gonococci on GCBDS medium.

\section{References}

Clowes, R. C., and Hayes, W. (1968). Experiments in Microbial Genetics Wiley, New York.

Counts, G. W., Seeley, L., and Beaty, H. N. (1971). Identification of an epidemic strain of Neisseria meningitidis by bacteriocin typing. J. infect. Dis., 124, 26-32.

Flynn, J., and McEnteggart, M. C. (1971). Bacteriocins from Neisseria gonorrhoeae and their possible role in epidemiological studies. J. clin. Path. 25, 60-61.

Goodwin, K., Levin, R. E., and Doggett, R. G. (1972). Autosensitivity of Pseudomonas aeruginosa to its own pyocin. Infect. and Immun. 6, 889-892. 
Hamon, Y., and Peron, Y. (1960). Etude du mode de fixation des colicins et des pyocins sur les bacteries sensibles. C.R. Acad. Sci. (Paris) 251, 1840-1842.

Kingsbury, D. T. (1966). Bacteriocin production by strains of Neisseria meningitidis. J. Bact. 91, 1696-1699.

Lawton, W. D., and Gaafar, H. A. (1973). Gonocin production by Neisseria gonorrhoeae. (Abstr.), Annual Meeting, American Society of Microbiology p. 128.

Reeves, P. (1965). The bacteriocins. Bact. Rev., 29, 24-45.

White L. A., and Kellogg, D. S., Jr. (1965). Neisseria gonorrhoeae identification in direct smears by a fluorescent antibodycounterstain method. Appl. Microbiol., 13, 171-174.

\section{Addendum}

Walstad, Reitz, and Sparling (Infect Immun, 10, $481-488,1974)$ have also recently observed growth inhibition among strains of $N$. gonorrhoeae due to longchain free fatty acids and monoacyl phosphatidylethanolamine, and have been unable to detect bacteriocin production by gonococci. 